\title{
Comparison of mechanochemical properties of myosin from carp ordinary and dark muscles
}

TSUYOSHI OKAGAKI,${ }^{1}$ MASAKI TAKAMI, ${ }^{1}$ HIROKI OHSHIMA, ${ }^{1}$ SUGIE HIGASHI-FUJIME, ${ }^{2}$ FumIAKI YANO, ${ }^{1}$ AND ATSUSHI OOI ${ }^{1}$

1Department of Bioresources, Mie University, Tsu-city, Mie 514-8507, Japan (okagaki@bio.mie-u.ac.jp), and 2Department of Life Science, Nagoya University, Nagoya 464-8602, Japan.

SUMMARY : Myosin isolated from carp ordinary and dark muscle was examined by in vitro motility assay, ATPase measurement, and electron microscopic observation of self assembled myosin filament. The sliding velocity of actin filament on ordinary and dark muscle myosin was 4.5 or $3.0 \mu \mathrm{m} / \mathrm{sec}$ at $25^{\circ} \mathrm{C}$, respectively. $\mathrm{V}_{\max }$ of actin-activated $\mathrm{Mg}^{2+}$-ATPase of ordinary myosin was 2- to 3-fold higher than that of dark myosin. Series of these two experiments at various ionic strength further revealed that ordinary myosin has higher affinity to actin filament than dark myosin. Not only the function of head, there are differences in the function of rod. Electron microscopic observation showed that ordinary myosin assembled into short faint filament. Whereas dark myosin formed regular bipolar filament, and number of the filament was much greater than that of ordinary one. The difference of the assembly was also confirmed by centrifugation of assembled myosin, followed by the analysis of the precipitate by SDS-PAGE. Thus, some important factor is required for complete assembly of ordinary myosin, and it is lacking in the preparation of myosin.

\section{KEY WORDS: actin, carp, motility assay, myosin, myosin filament, skeletal muscle}

\section{INTRODUCTION}

In vertebrates, there are two types of skeletal muscle, fast (white) and slow (red) muscle. The fast muscle works mainly anaerobic metabolism, and its fiber tend to be reserved for short bursts of intense contraction such as escape of reflex of a fish rather than sustained effort. The slow muscle fibers show slow twitch and rely on aerobic metabolism for their energy supply. It contains large quantities of myoglobin, a red, heme containing protein, that is able to combine with oxygen with a high affinity for maintaining an efficient supply of oxygen to their mitochondria ${ }^{1)}$. Contraction force of muscle is derived from the sliding movement between myosin and actin filaments. The myosin from fast muscle posseses higher ATPase activity than that from slow muscle, reflecting their contraction speed. It is reported that the molecular composition of these types of myosin is different, i.e. myosin for each muscle type has distinct heavy and light chains ${ }^{1}$. In case of most of fish, these fast and slow muscles are comparable to white ordinary muscle and dark muscle under the lateral line, respectively. Comparison of composition and biochemical properties of these types of myosin has been studied in mackerel ${ }^{2)}$, skipjack ${ }^{3)}$, and yellowtail ${ }^{4)}$. Recently, the sliding movement between myosin and actin can be observable by fluorescence microscopy equipped with very sensitive camera ${ }^{5)}$. This method, so called in vitro motility assay, is now widely used for characterization of various types of myosin. The aim of this study is to compare the function of ordinary and dark myosin precisely by biochemical and microscopic experiments such as in vitro motility assay, measurement of ATPase activity, observation and quantification of myosin filament assembly.

\section{MATERIALS AND METHODS}

Live specimens of carp, Cyprinus carpio, were purchased from Marusan Fisheries Co., Ltd., (Tsu-city, Mie, Japan) and brought to the laboratory. They were killed, and soon after dorsal muscle was removed. Myosin was prepared from ordinary and dark muscles separately as described ${ }^{6)}$. In some cases, the above preparation of myosin was further purified with ion exchange chromatography ${ }^{6)}$. Myosin was dissolved in 
$20 \mathrm{mM}$ K-pyrophosphate (pH 7.5), $1 \mathrm{mM}$ dithiothreitol (DTT), $2 \mathrm{mM}$ EDTA, and $2 \mu \mathrm{g} / \mathrm{ml}$ leupeptin and applied onto DEAE-Toyopearl $650 \mathrm{M}$ column $(\phi 1.6 \times 12 \mathrm{~cm})$ equilibrated with the above buffer. Myosin was eluted with linear gradient of $\mathrm{KCl}$ from 60 to $200 \mathrm{mM}$. The fractions containing myosin were pooled, dilalysed against $20 \mathrm{mM}$ MOPS (pH 7.0), $0.1 \mathrm{M} \mathrm{KCl}, 1 \mathrm{mM}$ DTT, $2 \mathrm{mM}$ EDTA, and $2 \mu \mathrm{g} / \mathrm{ml}$ leupeptin, and centrifuged at $100,000 \mathrm{~g}$ for $20 \mathrm{~min}$. The precipitated myosin was suspended in $0.6 \mathrm{M} \mathrm{KCl}$, $40 \mathrm{mM}$ Tris- $\mathrm{HCl}$ (pH 7.5), $2 \mathrm{mM}$ DTT, and $2 \mathrm{mM}$ EDTA, mixed with equal volume of cold glycerol, and stored at $-20^{\circ} \mathrm{C}$. Actin was purified from acetone-dried carp ordinary muscle and prepared as described ${ }^{5)}$. In vitro motility assay was performed at $25^{\circ} \mathrm{C}$ according to Takiguchi et al. ${ }^{5)}$ in $1 \mathrm{mM} \mathrm{ATP}$,

$2 \mathrm{mM} \mathrm{MgCl}_{2}, 25 \mathrm{mM} \mathrm{DTT}, 30 \mathrm{mM}$ imidazole (pH 7.6), $0.216 \mathrm{mg} / \mathrm{ml}$ glucose oxidase, $0.036 \mathrm{mg} / \mathrm{ml}$ catalase, and $4.5 \mathrm{mg} / \mathrm{ml}$ glucose. Actin-activated $\mathrm{Mg}^{2+}$-ATPase was performed at $25^{\circ} \mathrm{C}$ by the method of Hayashi ${ }^{7)}$ in 30-80 mM KCl, $20 \mathrm{mM}$ HEPES (pH 7.6), 1 mM ATP,

$2 \mathrm{mM} \mathrm{MgCl}_{2}, 0.11 \mu \mathrm{M}$ myosin with varying concentration of actin from 0.23 to $4.6 \mu \mathrm{M}$. For observation of myosin filament, myosin was assembled in $0.15 \mathrm{M} \mathrm{KCl}, 20 \mathrm{mM}$ HEPES (pH 7.4),

$1 \mathrm{mM}$ DTT at $1.1 \mu \mathrm{M}$. A drop of the solution was observed with a dark field light microscope without dilution. For electron microscopic observation, the solution was diluted to $0.22 \mu \mathrm{M}$ with the same buffer. A drop of the sample was placed on a collodion membrane on EM mesh which was coated with carbon, stained with $1 \%$ uranyl acetate, and the specimen was observed with an electron microscope JEM 1200C operated at $80 \mathrm{kV}$. The assembly was also quantified by centrifugation assay. Mixture of myosin at $1.1 \mu \mathrm{M}$ was centrifuged at 100,000 or $10,000 \mathrm{~g}$ for $20 \mathrm{~min}$ at $4^{\circ} \mathrm{C}$, then the supernatant and the precipitate were applied on SDS-PAGE, and the gel was stained with Coomassie brilliant blue. Bands of myosin heavy chain was densitometrically scanned, and the density was calculated by NIH image.

\section{RESULTS}

When actin filament labeled with phalloidine rhodamine was introduced onto the surface coated with ordinary muscle myosin, actin filament slid on the surface smoothly and continued the movement several ten micrometer. Average velocity of actin filament on ordinary myosin was $4.5 \mu \mathrm{m} / \mathrm{sec}$, whereas $3.0 \mu \mathrm{m} / \mathrm{sec}$ on dark myosin as shown in Fig. 1. Thus ordinary myosin had 1.5-times higher motile activity than dark myosin. This value is comparable to that of previous report $^{9,}{ }^{10)}$. The interaction of myosin and actin depends on ionic strength and is weakened by higher concentration of $\mathrm{KCl}$. The movement was ceased by increasing concentration of $\mathrm{KCl}$ as reported on rabbit skeletal muscle myosin ${ }^{5)}$. The movement was not observed over critical concentration of $\mathrm{KCl}$. The value was $80 \mathrm{mM} \mathrm{KCl}$ for ordinary myosin, and $70 \mathrm{mM} \mathrm{KCl}$ for dark myosin. Over $100 \mathrm{mM} \mathrm{KCl}$, any actin filaments could not attached to the surface coated with either types of myosin. These results indicate that there is difference between ordinary and dark myosin not only in the sliding velocity but also in the affinity to actin filament.
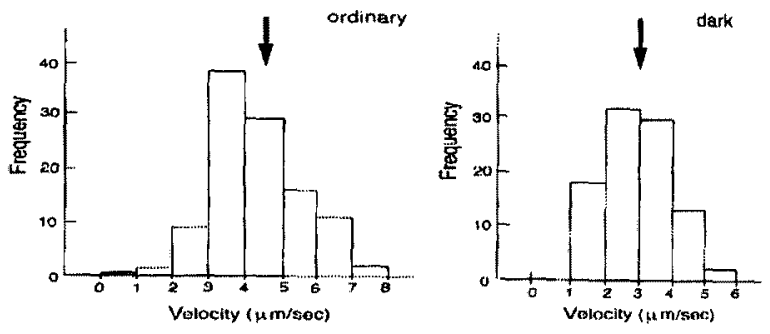

Fig. 1 Histogram of sliding velocity of actin filament on myosin- coated surface. Ordinary (left) and dark myosin (right). Arrows indicate average of velocity. The data were obtained by 110 different records of the movement.

Myosin ATPase is activated by several divalent or monovalent cation. There are three types of ATPase, $\mathrm{Ca}^{2+}-\mathrm{Mg}^{2+}$-, and $\mathrm{K}^{+}$-EDTA-ATPase. In these three, only $\mathrm{Mg}^{2+}$-ATPase is activated by the presence of actin, so that this ATPase activity is thought to be coupled to the movement. As shown in Fig. 2, the activity was increased with increasing concentration of actin, and seems to be saturated over $2.3 \mu \mathrm{M}$. We measured the ATPase activity by changing $\mathrm{KCl}$ concentration to estimate the affinity of these two types of myosin to actin filament. By increasing concentration of $\mathrm{KCl}$, the activity of both types of myosin was reduced. We analyzed these data by Lineweaver-Burk plot to obtain two parameters, $\mathrm{V}_{\max }$ and $\mathrm{K}_{\mathrm{m}}$. The $\mathrm{V}_{\max }$ of ordinary myosin was $0.15,0.16$, and $0.12 \mu \mathrm{mol} \mathrm{Pi} / \mathrm{min}$-mg at 40 , $60,80 \mathrm{mM} \mathrm{KCl}$, respectively. The corresponding value of $K_{m}$ was $0.38,0.81$, and $1.43 \mu \mathrm{M}$ at $40,60,80$ 
$\mathrm{mM} \mathrm{KCl}$, respectively. The $\mathrm{V}_{\max }$ of dark myosin was $0.07,0.09$, and $0.03 \mu \mathrm{mole} \mathrm{Pi} / \mathrm{min}-\mathrm{mg}$ at $40,60,80$ $\mathrm{mM} \mathrm{KCl}$, respectively. The Michaelis constant $\mathrm{K}_{\mathrm{m}}$ was $0.62,0.90$, and $1.88 \mu \mathrm{M}$ at $40,60,80 \mathrm{mM} \mathrm{KCl}$, respectively. As expected by motility assay, $V_{\max }$ of ordinary myosin was higher than that of dark myosin. The $\mathrm{K}_{\mathrm{m}}$ of ordinary myosin was larger than dark myosin, suggesting the latter has lower affinity to actin filament.

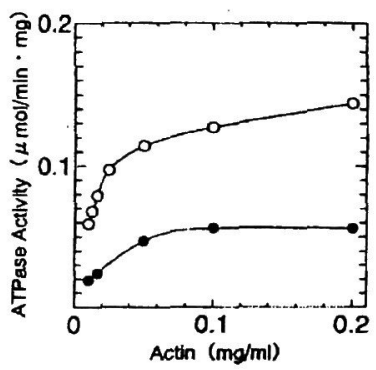

Fig. 2 Actin-activated ATPase activity in $40 \mathrm{mM} \mathrm{KCl}$. The data of ordinary (open circle) and dark myosin (closed circle) were plotted against the concentration of actin.

To observe myosin filament, myosin was assembled to form filament. By dark field light microscopic observation, the solution of ordinary myosin appeared to be spots of low intensity or large aggregates. Whereas many spots with high intensity that is corresponding to bipolar filament could be seen in the solution of dark myosin (data not shown). To observe fine structure of myosin filament, the solution was examined with an electron microscope. Ordinary myosin assembled into short, faint filaments, and these filaments seemed to be easy to gather (Fig. 3a). Dark myosin formed regular bipolar filament (Fig. 3b). Number of filament in the solution of dark myosin was much greater than that of ordinary myosin. To confirm this, we performed centrifugation experiment. When solution of myosin was centrifuged at $100,000 \mathrm{~g}$, we could not find significant difference in these two myosin (Fig. 4). But in the centrifugation at 10, $000 \mathrm{~g}$, amount of precipitate of dark myosin was about $20 \%$ larger than that of ordinary myosin (data not shown).

Since myosin preparation purified by repeating of assembly and disassembly contains several contaminating proteins ${ }^{11}$. To separate myosin from these contaminating proteins and examine properties of myosin without interference of these proteins, we applied these myosin preparations on

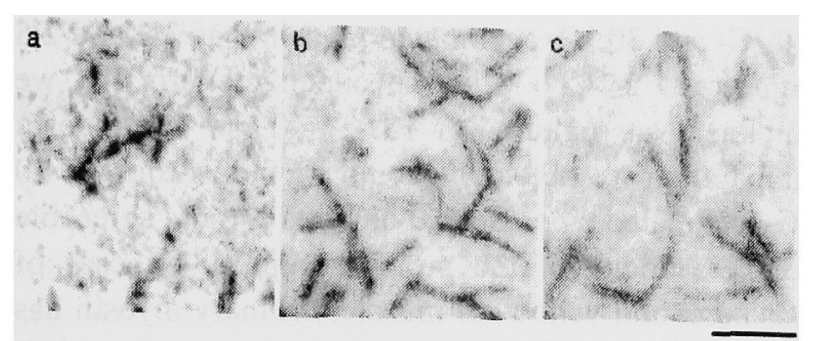

DEAE-Toyopearl column chromatography ${ }^{11)}$. In this chromatography, the contaminants were eluted as flow through, remaining myosin that was still adsorbed to the resin

Fig. 3 Electron micrographs of myosin filament. Myosin from carp ordinary (a), carp dark (b) and chicken breast muscle, respectively. Bar under $C$ indicates scale of $1 \mu \mathrm{m}$.

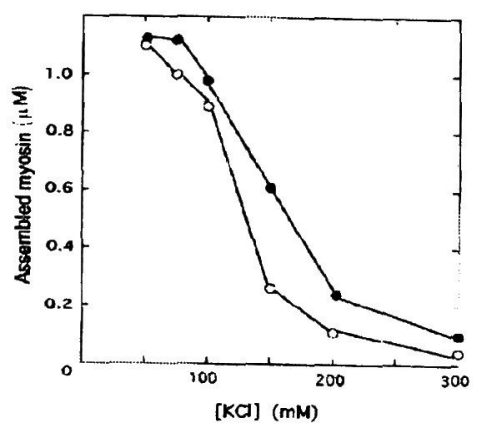

Fig. 4 Centrifugation assay of myosin filament at $\mathrm{pH} 7.4$. Ordinary or dark myosin were assembed in various concentration of $\mathrm{KCl}$, and then centrifuged at $100,000 \mathrm{~g}$ for 20 min. The concentration of assembled myosin was estimated by the amount of precipitated myosin. Ordinary (open circle) and dark myosin (closed circle).

(data not shown). Adsorved myosin was eluted with $100-150 \mathrm{mM} \mathrm{KCl}$. When each of the column-purified ordinary and dark myosin was assembled, we could still observe the difference of the shape of myosin filament as in the case shown in Fig. 3 (data not shown). Thus, the difference of assembly of these two types of myosin might be derived from the properties of myosin itself.

\section{DISCUSSION}

We report here the sliding movement on ordinary and dark myosin. Carp has three types of myosin heavy chain gene in ordinary muscle, and their expression is depending on temperature acclimation ${ }^{10)}$. Chaen et $a l .{ }^{9)}$ reported that sliding velocity of actin filament on 
$10{ }^{\circ} \mathrm{C}$ - and $30^{\circ} \mathrm{C}$ - acclimated myosin was 3.3 and 2.5 $\mu \mathrm{m} / \mathrm{sec}$ at $23^{\circ} \mathrm{C}$. Live specimen of carp that we obtained was cultured at $10-14{ }^{\circ} \mathrm{C}$, so that myosin preparation we obtained should be the isoform of 10 ${ }^{\circ} \mathrm{C}$-acclimated type. So that our data is quite agreeable to the velocity of the previous report. In case of mackerel and yellowtail muscle, ordinary myosin has 5- or 3-fold higher in ATPase activity than dark myosin $^{2,4)}$. But in case of carp, we could not observe such significant difference between ordinary and dark myosin. The difference of these two types of myosin may vary depending on fish species.

The assembly of ordinary or dark myosin was sensitive to $\mathrm{pH}$ or concentration of $\mathrm{KCl}$ when it was examined by centrifugation assay. This profile was quite similar to the previous report ${ }^{12)}$. The ordinary myosin did not form regular, bipolar filaments (Fig. 3). We speculate that some important factor to stabilize the filament is required for assembly of ordinary myosin. Matsuura and. Arai succeeded in isolating native thick filament from carp dorsal muscle ${ }^{13)}$. When the preparation of filament was put into the dialysis bag and dialyzed against high salt buffer, then low salt buffer, the native filament was once disassembled by high salt and reassembled to form regular bipolar filament by low salt solution. This finding indicates that the preparation is containing all component that is required for the formation of bipolar thick filament. Until now several myosin-binding proteins have been purified, and their function is characterized in mammalian or avian skeletal muscle ${ }^{11)}$. Identification of such myosin-binding protein in fish muscle will be required for the complete understanding of the formation of myosin filament in fish muscle.

\section{ACKNOWLEDGEMENTS}

We thank to Mr. H. Toyota (Osaka University) for providing us computer program for calculation of sliding velocity. We also thank to Prof. H. Hotani (Nagoya University) for permitting us to use image analyzer for analysis of in vitro motility assay.

\section{REFERENCES}

1. Bray D. Cell Movements. Garland Publishing Inc. (New York, London) 1992.

2. Watabe S, Hashimoto $\mathrm{K}$. Myosin from white and dark muscles of mackerel. J. Biochem. 1980; 87: 1491-1499.

3. Ochiai $Y$, Watabe $S$, Hashimoto $K$. Isolation and characterization of myosin light chains from skipjack ordinary muscle. Bull. Jap. Soc. Sci. Fish. 1984; 50; 1729-1733.

4. Watabe S, Hashimoto K, Watanabe S. The pH-dependency of myosin ATPases from yellowtail ordinary and dark muscles. J. Biochem. 1983; 94: 1867-1875.

5. Takiguchi $\mathrm{K}$, Hayashi $\mathrm{H}$, Kurimoto $\mathrm{E}$, Higashi-Fujime S. In vitro motility of skeletal muscle myosin and its proteolytic fragments. J. Biochem. 1990; 107:671-679.

6. Reinach F, Masaki T, Shafiq S, Obinata T, Fischman DA. Isoforms of C-protein in adult chicken skeletal muscle:detection with monoclonal antibodies. J. Cell Biol.1982; 95:78-84.

7. Okagaki T, Weber FE, Fischman DA, Vaughan KT, Mikawa $\mathrm{T}$, Reinach FC. The major myosin-binding domain of skeletal muscle MyBP-C (C protein) resides in the COOH-terminal, immunoglobulin $\mathrm{C} 2$ motif. J. Cell Biol. 1993; 123:619-626.

8. Hayashi M. Interference with the Murphy-Riley orthophosphate determination method in the application to ATPase assay. Anal. Biochem. 1976; 76:9-15.

9. Chaen S, Nakaya M, Guo X-F, Watabe S. Lower activation energy for sliding of F-actin on a less thermostable isoform of carp myosin. J.Biochem. 1996; 120:788-791.

10. Kikuchi K, Muramasu M, Hirayama Y, Watabe S. Characterization of the carp myosin heavy chain multigene family. Gene. 1999; 228: 189-196.

11. Starr R, Offer G. Polypeptide chains of intermediate molecular weight in myosin preparations. FEBS Lett. $1971 ; 15: 40-44$.

12. Matsuura M, Arai K. Effect of $\mathrm{pH}$ on filament-forming ability and biochemical activity of fish myosins. Bull. Jap. Soc. Sci. Fish. 1986; 52:1657-1663.

13. Matuura M, Arai K. Preparation and properties of myosin native thick filaments from fish dorsal muscle. Nippon Suisann Gakkaishi. 1987; 53: 1073-1082. 